\title{
A Satisfaction Degree Evaluation Model of Knowledge Payment Platform for College Students in Guangzhou City
}

\author{
Qiansheng Zhang*, Yaxian Chen, Guoming Wu, Huahong Chen, Xiaoya Sun, Huijuan Zang
}

School of Mathematics and Statistics, Guangdong University of Foreign Studies, Guangzhou, P. R. China

Email address:

zhqiansh01@126.com (Qiansheng Zhang)

${ }^{*}$ Corresponding author

\section{To cite this article:}

Qiansheng Zhang, Yaxian Chen, Guoming Wu, Huahong Chen, Xiaoya Sun, Huijuan Zang. A Satisfaction Degree Evaluation Model of Knowledge Payment Platform for College Students in Guangzhou City. American Journal of Mathematical and Computer Modelling. Vol. 5, No. 1, 2020, pp. 22-28. doi: 10.11648/j.ajmcm.20200501.14

Received: February 25, 2020; Accepted: March 24, 2020; Published: April 14, 2020

\begin{abstract}
With the rapid development of knowledge information and internet technology, a variety of online knowledge paid products and knowledge payment platforms are widely used by college students. The satisfaction evaluation of knowledge payment platform not only helps college students choose a suitable knowledge payment platform, but also helps the knowledge payment platform improve competitiveness and standardization. This paper collects customer satisfaction data by designing questionnaires and conducting customer satisfaction surveys. Using statistical analysis methods such as descriptive statistics, parameter testing and reliability analysis, the customer satisfaction data are analyzed from different dimensions. Based on American customer satisfaction index (ACSI) and the characteristics of knowledge payment, content quality, technical quality, update frequency and advertising marketing quality are extracted as important factors for satisfaction evaluation. Then, a satisfaction evaluation model of knowledge payment platform is constructed to evaluate the satisfaction degree of college students on the knowledge payment platform by employing factor analysis and multivariable regression analysis. The proposed model can predict the development trend of knowledge payment platforms and provide valuable suggestions for the healthy development and the selection of knowledge payment platforms.
\end{abstract}

Keywords: Knowledge Payment Platform, Customer Satisfaction Index, Satisfaction Degree Model, Factor Analysis, Multivariable Analysis

\section{Introduction}

With the rapid development of Internet technology, the number of users in the knowledge payment industry in China has grown rapidly from 50 million in 2015 to 360 million in 2019, and is expected to approach 500 million in 2021 [1]. The emergence of various knowledge payment platforms has aroused widespread concern among college students on knowledge acquisition. The knowledge payment industry in China can be subdivided into different functional platform industries such as knowledge e-commerce, community live broadcast, social quiz, and lecture courses [2]. However, due to the uneven quality of knowledge payment products, people's satisfaction with knowledge payment platforms varies. In recent years, some scholars have conducted a lot of survey researches of knowledge payment platforms. For example, Zhang [3] made a summary of the relevant literature research on knowledge payment platforms and put forward suggestions for the development of knowledge payment platforms in China. By comparing the development status of domestic and foreign knowledge payment platforms, Yang [4] analyzed the differences between domestic and foreign knowledge payment platforms in terms of payment models, operation methods and user services. Some scholars also studied on the platform users. For example, Ren et al. [5] have found that there are different preferences and intensities among groups with knowledge payment behavior. Zhao et al. [6] constructed a model of influencing factors of knowledge payment behavior for Q\&A platform users and conducted empirical research. Zhao and Zhou et al. [7] examined the role of knowledge contributor characteristics and reputation on trust and user pay decisions in paid Q\&A. In 1965, American scholar Cardozo first introduced the concept of customer satisfaction into the business field [8]. Since then, many 
scholars discussed the development status, influencing factors, business models and psychological needs of knowledge payment products. However, there are few researches on consumer satisfaction evaluation model and the development strategy of knowledge payment platforms.

Since college students are not only the main force of knowledge consumption but also the guide of consumption trends in the future knowledge market, this paper will take college students in Guangzhou university town as example to investigate the satisfaction evaluation model of knowledge payment platform. By issuing questionnaires, analyzing data and establishing model, we study the willingness and satisfaction of college students on the knowledge payment platform and its influencing factors. Finally, we explore the prospect value of knowledge payment platform and propose some reasonable marketing strategies for the future development of knowledge payment platforms.

\section{Satisfaction Evaluation Model of Knowledge Payment Platform Based on ACSI}

\subsection{Determination of Structural Variables of Satisfaction Degree Evaluation Model}

Based on American customer satisfaction index (ACSI) model [9], this paper first determines the structural variables in the logical model of college students' satisfaction with the knowledge payment platform $[10,11]$. Since the users have low familiarity and do not have a deep understanding of knowledge payment platform, and there is no unified standard for evaluation and packaging of knowledge payment platform, we are unable evaluate satisfaction degree from customer complaint and customer expectation variables in the ACSI model. Therefore, this paper removes the two factors of customer complaint and customer expectation from ACSI model. We only keep perceived quality, perceived value, customer loyalty, customer satisfaction as the structural variables of satisfaction model of knowledge payment platform. Due to the variety of products of the knowledge payment platform, the perceived quality comprises six structural variables of content coverage, update frequency, exclusivity, operability, security, advertising marketing. Perceived value is regarded as the price-performance ratio, student satisfaction is the core variable in the proposed satisfaction evaluation model.

\subsection{Structural Variable Analysis and Model Assumptions}

Content coverage including the type of knowledge published by the knowledge payment platform, the depth of the knowledge, the uniqueness of the knowledge, the timeliness and the coverage of the content will have a direct impact on user satisfaction. Update frequency including the frequency and pace of update of the knowledge payment platform has become an important potential factor affecting user satisfaction. The knowledge payment platform can provide customers with exclusive knowledge to meet customer demand and retain more customers. This shows that exclusivity has a significant effect on customer satisfaction. Operability including the effectiveness and efficiency of the operation interface is a direct perception of the user satisfaction with the platform [12]. Security of knowledge payment platform affects whether users are willing to use knowledge payment platforms, which has a profound effect on user satisfaction. Advertising marketing including the authenticity of the advertisement, the content of the advertisement and the amount of the advertisement will affect the customer's impression of the platform and will indirectly affect customer satisfaction [13]. Cost-effectiveness, namely the price-performance ratio of the knowledge payment platform, will affect the demand for the product and have a greater impact on user satisfaction [14]. User loyalty can reflect customer satisfaction with the knowledge payment platform [15].

Based on the above variable analysis of the model factors, this paper makes the following assumptions in Table 1 about the relationship between the structural variables in the satisfaction model of knowledge payment platforms for college students.

Table 1. Relevant assumptions of the satisfaction evaluation model.

\begin{tabular}{|c|c|}
\hline Structure variable & Hypothetical content \\
\hline \multirow{2}{*}{ Content coverage } & The wider the content coverage, the more satisfied the user is \\
\hline & The finer the content coverage, the more satisfied the user is \\
\hline Update frequency & The higher the update frequency, the more satisfied the user is \\
\hline Exclusivity & The higher the exclusivity, the more satisfied the user is \\
\hline Operability & The more convenient the operation, the more satisfied the user is \\
\hline \multirow{3}{*}{ Advertising and marketing } & The less ad marketing, the more satisfied users are \\
\hline & The better the advertising content, the more satisfied the user is \\
\hline & The more authentic the advertising content, the more satisfied the user is \\
\hline Cost performance & The higher the cost performance, the more satisfied the user is \\
\hline Loyalty & The higher the user loyalty is, the more satisfied the user is \\
\hline
\end{tabular}




\section{Questionnaire Sampling Design}

\subsection{Questionnaire Structure and Scale Design}

The formal questionnaire of this research is divided into three parts involving 22 questions. The first part is the opening part including the title of the questionnaire and the concept introduction, which explain the purpose and purpose of the survey and eliminate the doubts and concerns of respondents. The second part is the basic information of the object and the usage of knowledge payment. The third part of questionnaire includes some scale items for satisfaction evaluation. Here we use Likert level 5 attitude scale measurement, rating 1-5 denote strongly disagree, disagree, general, agree and strongly agree, respectively. The detailed scale structure design [16] is shown in the following Table 2.

Table 2. Scale structure.

\begin{tabular}{|c|c|c|c|}
\hline Latent variable & Observed variable & Measure item & Reference source \\
\hline \multirow{7}{*}{ Perceived quality } & Exclusivity & High information exclusivity of knowledge payment platform & \multirow{5}{*}{$\begin{array}{l}\text { Davis (1989) [17], } \\
\text { Kim (2007) }\end{array}$} \\
\hline & & The content of knowledge paid products opened my horizons & \\
\hline & Content coverage & $\begin{array}{l}\text { The content of the knowledge payment platform is very helpful for me to } \\
\text { complete the task }\end{array}$ & \\
\hline & Update frequency & Knowledge payment platform is not updated frequently & \\
\hline & \multirow{2}{*}{ Operability } & I find it very convenient to use knowledge paid products & \\
\hline & & It's very easy to find the knowledge paid product I want & \multirow[t]{2}{*}{$\operatorname{Kim}(2007)$} \\
\hline & $\begin{array}{l}\text { Advertising and } \\
\text { marketing }\end{array}$ & $\begin{array}{l}\text { The knowledge marketing platform's advertising content is not good } \\
\text { Advertising marketing content of knowledge paid platform is not real } \\
\text { There is a lot of advertising marketing on knowledge paid platforms }\end{array}$ & \\
\hline Perceived value & Cost nerformar & I paid for the knowledge paid product, I think it's worth it & J Wu S Wang \\
\hline Percenved value & Cost perrormance & The time and energy I paid for learning the paid product, I think it's worth it & (2005), Kim (2007) \\
\hline User lovalty & Lovalty & $\begin{array}{l}\text { In the future I will try to purchase knowledge paid products / I will continue to } \\
\text { purchase knowledge paid products in the future }\end{array}$ & $\begin{array}{l}\text { Davis (1989), Kim } \\
\text { (2007) }\end{array}$ \\
\hline User loyalty & Loyalty & $\begin{array}{l}\text { When someone asks for advice about my paid product, I would recommend } \\
\text { buying }\end{array}$ & \\
\hline Customer satisfaction & Overall satisfaction & I am very satisfied with the knowledge payment platform & \\
\hline
\end{tabular}

\subsection{Descriptive Statistics Analysis}

Since the total number of college students in Guangzhou city adds up to $\mathrm{N}=200,000$, we use a random sampling of schools and gender to conduct a questionnaire survey. First, according to the central limit theorem and the condition that the accuracy confidence is $95 \%$, we calculate the sample size should be 406 . In order to avoid the screening of invalid samples when analyzing the data, we issue the total of 478 questionnaires survey for college students in Guangzhou city where $42.7 \%$ for boys and $57.3 \%$ for girls. Finally, we get 431 qualified questionnaires. The results of random questionnaire survey are displayed as the following figures $1-5$.

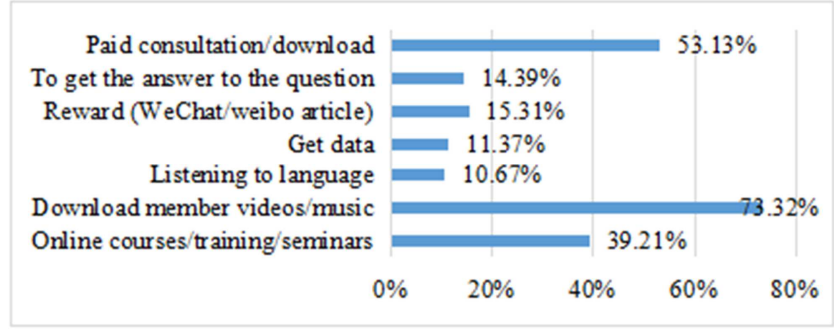

Figure 1. Usage of knowledge payment products by college students.

From Figure 1 we see that more than $70 \%$ of the respondents pay for the entertainment information of video and audio, and nearly half of them pay for downloading related materials. Paying has a certain degree of understanding and their evaluation is more convincing.

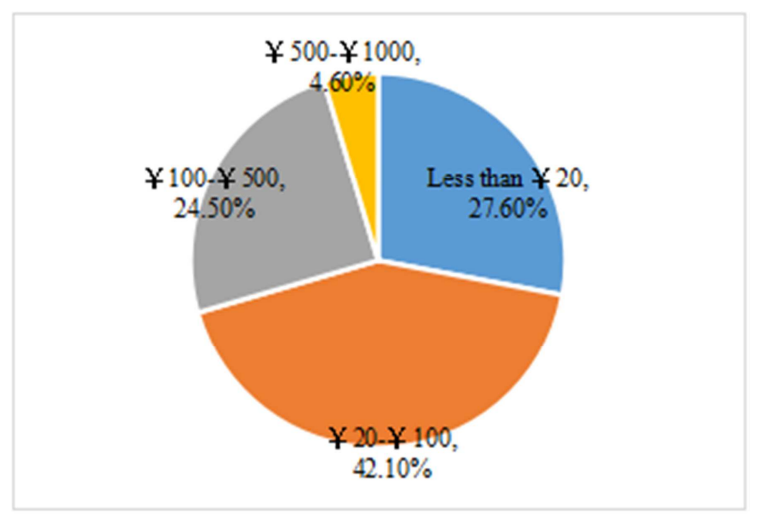

Figure 2. College students' spending on knowledge payment platform.

From the survey respondents' data on spending or willingness to pay for knowledge-based products in Figure 2, one can see that most college students are reluctant to invest too much money in knowledge-based paid products.

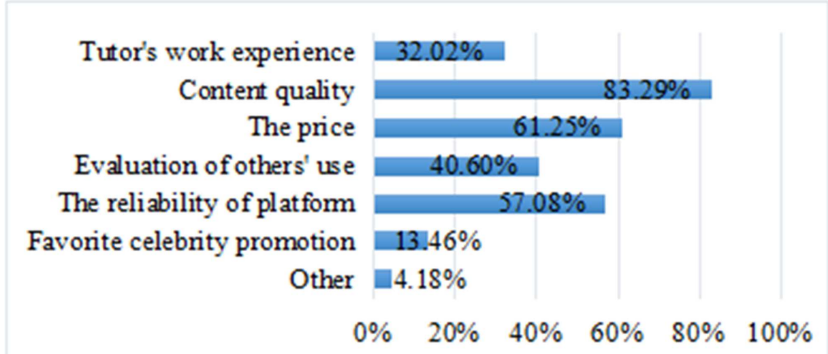

Figure 3. Factors affecting the purchase of knowledge paid products. 
From the perspective of the factors that affect knowledge payment in figure 3 , we know that the quality, price and reliability of the paid products largely affect whether people buy knowledge payment products. At the same time, the evaluation of a knowledge payment platform by others also affects whether consumers buy or use the product to a certain extent.

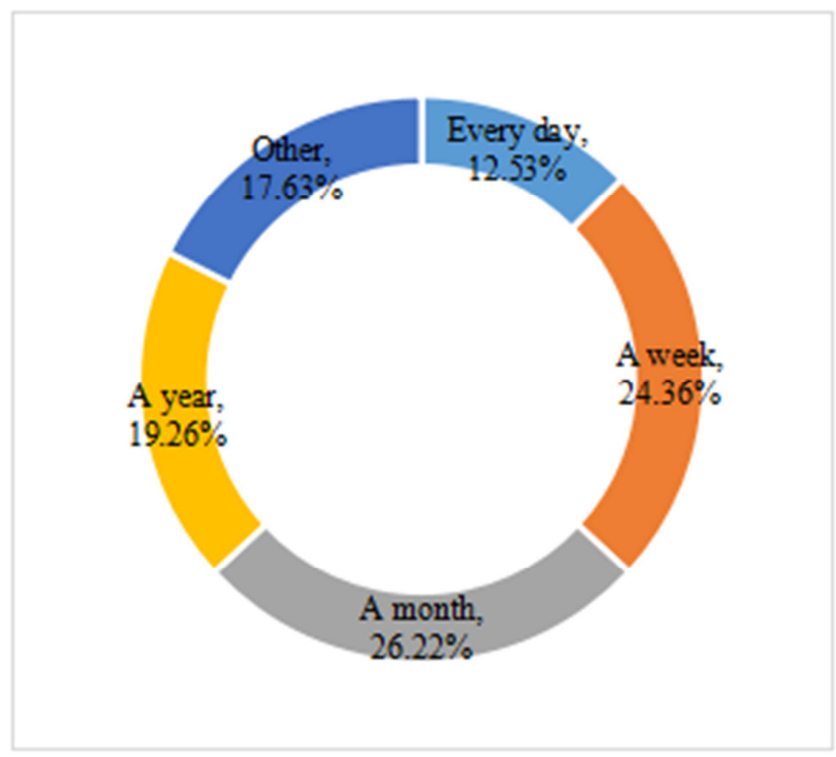

Figure 4. Frequency of college students using knowledge paid products.

From the data in figure 4 one can see that more than $60 \%$ of the respondents use knowledge paid products more than monthly, which indicate that the use frequency of knowledge paid products is not low, and knowledge paid products play a significant role in life.

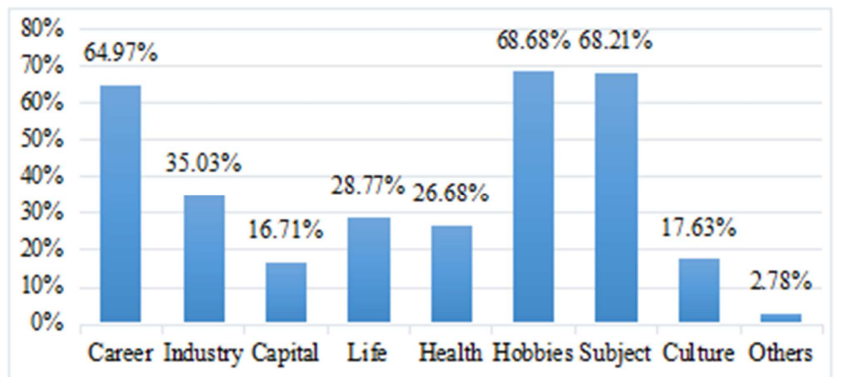

Figure 5. Contents of college students learning by knowledge payment platform.

From figure 5 of the contents that college students are willing to learn by payment platform, people tend to pay for knowledge products that are relevant to them or that they like, such as career development, professional disciplines and hobbies.

In summary, from figures 1-5 of the distribution characteristics of the sample one can see that this sample has a better representativeness, which provides a reliable guarantee for further measurement and analysis of college students' knowledge and attitude towards knowledge payment.

\section{Construction of Satisfaction Model Based on Multivariate Regression}

\subsection{Reliability Analysis}

Reliability reflects the stability and consistency of the measurement questionnaire results. The following results can be obtained from the data analysis by SPSS. The Cronbach coefficient of the entire questionnaire in Table 3 reaches 0.781 , which indicates that the entire questionnaire is more credible. The reliability coefficients of the three latent variables of perceived quality, perceived value, and user loyalty are all greater than 0.7 , indicating that the reliability of the scale is good.

Table 3. Reliability analysis.

\begin{tabular}{lll}
\hline Latent variable & $\begin{array}{l}\text { Kronbach } \\
\text { Alpha }\end{array}$ & $\begin{array}{l}\text { Number of } \\
\text { observed variables }\end{array}$ \\
\hline Perceived quality & .738 & 10 \\
Perceived value & .766 & 2 \\
User loyalty & .718 & 2 \\
Total scale reliability & .877 & 15 \\
Questionnaire total reliability & .781 & 22 \\
\hline
\end{tabular}

\subsection{Validity Analysis}

Validity refers to the degree of correlation between research observations and true values. The closer the KMO value is to 1 , the more suitable the sample data is for factor analysis. From the information in Table 4 we see that the significance value of Bartlett sphericity test is 0 , which indicates a significant difference between the correlation coefficient matrix and the identity matrix. So, the structural variables have significant correlation.

Table 4. KMO and Bartlett test.

\begin{tabular}{lll}
\hline KMO inspection & & $\mathbf{. 8 1 9}$ \\
\hline \multirow{3}{*}{ Bartlett sphericity tes } & Approximate chi-square & 1083.839 \\
& Degrees of freedom & 28 \\
& Sig & .000 \\
\hline
\end{tabular}

\subsection{Determination of Satisfaction Evaluation Factors Based on Factor Analysis}

From Table 4 one can see that the KMO value is 0.819 , which also indicates that the original structure variables are suitable for performing factor analysis to determine the satisfaction evaluation factors. The detailed factor analysis results are shown in the following Tables 5-7 by using SPSS 23.0.

Table 5. Common Factor Variance.

\begin{tabular}{lll}
\hline & initial & extract \\
\hline Exclusivity & 1.000 & .836 \\
Content coverage & 1.000 & .792 \\
Operability & 1.000 & .724 \\
safety & 1.000 & .822 \\
Update frequency & 1.000 & .902 \\
Advertising and marketing & 1.000 & .865 \\
Cost performance & 1.000 & .709 \\
Loyalty & 1.000 & .632 \\
\hline
\end{tabular}


According to the correlation coefficient matrix of the original variables, the principal component analysis method is used to extract the factors. From the above Table 5, one can see that the commonality of each variable exceeds 0.6 , and the information loss of each variable is less. Therefore, the overall effect of this factor extraction is ideal.

Table 6. Total variance explanation.

\begin{tabular}{llllll}
\hline \multirow{2}{*}{ ingredient } & \multicolumn{2}{l}{ Initial eigenvalue } & \multicolumn{3}{c}{ Sum of squared rotation loads } \\
\cline { 2 - 6 } & total & Variance percentage & Cumulative\% & total & Variance percentage \\
\hline 1 & 3.540 & 44.252 & 44.252 & 1.915 & 23.944 \\
2 & 1.065 & 13.317 & 57.569 & 1.644 & 20.556 \\
3 & .882 & 11.021 & 68.590 & 1.471 & 18.388 \\
4 & .796 & 9.948 & 78.538 & 1.252 & 15.650 \\
5 & .602 & 7.521 & 86.058 & & \\
6 & .458 & 5.722 & 91.781 & & \\
7 & .334 & 4.172 & 95.953 & & \\
\hline
\end{tabular}

As can be seen from Table 6, the cumulative variance of four factors is $78.538 \%$, i.e., the four factors provide $78.538 \%$ of the information of original eight variables, which meets the requirements of principal component analysis. Hence, we will extract four factors without loss much information in the proposed satisfaction degree evaluation model of knowledge payment platform.

Table 7. Component matrix after rotation.

\begin{tabular}{lllll}
\hline & $\mathbf{1}$ & $\mathbf{2}$ & $\mathbf{3}$ & $\mathbf{4}$ \\
\hline Exclusivity & .896 & .134 & .063 & .108 \\
Content coverage & .834 & .207 & .153 & .175 \\
Operability & .305 & .771 & .010 & .189 \\
safety & .074 & .897 & .073 & .078 \\
Update frequency & .096 & .008 & .944 & .052 \\
Advertising and marketing & .089 & .088 & -.009 & .922 \\
Cost performance & .400 & .334 & .405 & .524 \\
Loyalty & .377 & .254 & .406 & .510 \\
\hline
\end{tabular}

Also, from Table 7 one can see that the variable exclusivity and content coverage have higher load in the first factor, which is interpreted as the content quality. The variable operability and security have higher load in the second factor, which is interpreted as the technical quality; The variable update frequency has a higher load in the third factor, which is interpreted as the update frequency. The variable advertising marketing, Cost performance and Loyalty have higher load in the fourth factor, which is interpreted as the marketing quality. The factor load diagram after rotation shows that the factor loads are all greater than 0.5 , indicating that their reliability is reasonable. Therefore, these four factors can be used as indicators of user satisfaction with knowledge payment platforms.

\subsection{Establishment of Satisfaction Evaluation Model by Multivariable Regression}

We select the satisfaction of knowledge payment platform as the dependent variable and record it as y. And we choose the obtained four important factors by factor analysis as independent variables. The regression relationship between the variables can be approximated by a linear function. The multivariable regression equation of the satisfaction degree evaluation model of knowledge payment platform can be constructed as follows.

$$
\mathrm{y}=\beta_{0}+\beta_{1} \mathrm{x}_{1}+\beta_{2} \mathrm{x}_{2}+\beta_{3} \mathrm{x}_{3}+\beta_{4} \mathrm{x}_{4}+\mu
$$

where $y$ represents the satisfaction of knowledge payment platform; $\mathrm{x}_{1}$ represents the content quality factor; $\mathrm{x}_{2}$ represents the technical quality factor; $\mathrm{x}_{3}$ represents the update frequency factor; $\mathrm{x}_{4}$ represents the marketing quality, $\mu$ represents the random error term; $\beta_{\mathrm{i}}(\mathrm{i}=0,1,2,3,4)$ represents the overall regression coefficient.

By using the stepwise regression algorithm in SPSS 23.0, we get the estimated regression coefficients results as $\operatorname{sh} 17$ own in the following Table 8. The coefficients of content quality, technical quality, update frequency and marketing quality are $\beta_{1}=0.472, \beta_{2}=0.233, \beta_{3}=0.161$, and $\beta_{4}=0.188$. The satisfaction evaluation regression model is

$$
\hat{y}=3.251+0.472 \mathrm{x}_{1}+0.233 \mathrm{x}_{2}+0.161 \mathrm{x}_{3}+0.188 \mathrm{x}_{4}
$$

Table 8. Regression coefficient result.

\begin{tabular}{llllll}
\hline & \multicolumn{2}{l}{ Unstandardized coefficient } & Normalization coefficient & t & \multirow{2}{*}{ sig } \\
\cline { 2 - 5 } & $\mathbf{B}$ & Standard error & Beta & 109.636 & .000 \\
\hline Constant & 3.251 & .030 & .558 & 15.895 & .000 \\
Content quality $\mathrm{x}_{1}$ & .472 & .030 & .276 & 7.861 & .000 \\
Technical quality $\mathrm{x}_{2}$ & .233 & .030 & .191 & 5.437 & .000 \\
Update frequency $\mathrm{x}_{3}$ & .161 & .030 & .223 & 6.337 & .000 \\
Marketing Quality $\mathrm{x}_{4}$ & .188 & .030 & & & \\
\hline
\end{tabular}




\subsection{Model Testing}

First, we can calculate the random error of multivariable linear regression to estimate the accuracy of the regression equation by the following formula

$$
S^{2}=\frac{\sum_{\mathrm{t}=1}^{\mathrm{n}} \mathrm{e}_{\mathrm{t}}{ }^{2}}{\mathrm{n}-\mathrm{k}}=161.394 /(431-5)=0.380
$$

where $n=431$ is the number of sample observations, $k=5$ is the number of regression coefficients, and $e_{t}$ is the residual. The calculated standard error S is very small, so the obtained satisfaction degree regression model is representative.

Second, we test the goodness-of-fit by the adjusted determination coefficient of the regression equation to evaluate the degree of fit as follows.

$$
\bar{R}^{2}=1-\frac{\sum \mathrm{e}_{\mathrm{t}}{ }^{2} /(n-k)}{\sum_{t=1}^{n}\left(y_{t}-\bar{y}\right)^{2} /(n-1)}=1-\frac{n-1}{n-k}\left(1-R^{2}\right)
$$

where $\mathrm{R}$ square is the determination coefficient.

Table 9. Regression Model summary.

\begin{tabular}{lllll}
\hline model & R & R square & $\begin{array}{l}\text { Adjusted } \\
\text { R square }\end{array}$ & $\begin{array}{l}\text { Standard } \\
\text { estimation error }\end{array}$ \\
\hline Step by step & .919 & .845 & .842 & .2909 \\
\hline
\end{tabular}

From the above Table 9, one can see that the adjusted determination coefficient $\bar{R}^{2}=0.842$, which indicates that the goodness-of-fit is good.
Thirdly, we make significance $F$ test based on samplebpopulation.

Assuming that the overall regression equation is not significant, i.e., $\mathrm{H}_{0}: \beta_{0}=\beta_{1}=\beta_{2}=\beta_{3}=\beta_{4}=0$.

Further we use SPSS 23 do ANOVA variance analysis, and the ANOVA result is shown in Table 10.

Table 10. ANOVA result.

\begin{tabular}{llllll}
\hline & $\begin{array}{l}\text { Sum of } \\
\text { squares }\end{array}$ & $\begin{array}{l}\text { Degrees of } \\
\text { freedom }\end{array}$ & $\begin{array}{l}\text { Mean } \\
\text { square }\end{array}$ & F & sig \\
\hline Regression & 145.539 & 4 & 36.385 & 96.035 & .000 \\
Residual & 161.398 & 426 & .379 & & \\
Total & 306.937 & 430 & & & \\
\hline
\end{tabular}

From Table 10 one can see that $\mathrm{F}=96.035$, sig $<0.05$ at the significance level of $5 \%$, so $\mathrm{x}_{1}, \mathrm{x}_{2}, \mathrm{x}_{3}$ and $\mathrm{x}_{4}$ have a significant impact on $\mathrm{y}$, and the linear regression model is significant.

Finally, we do significance $\mathrm{T}$ test based on regression coefficient.

We calculate the $t$ statistic of coefficient as follows.

$$
\mathrm{t}_{\beta_{\mathrm{j}}}=\frac{\beta_{\mathrm{j}}}{S_{\beta_{j}}}, j=1,2,3,4
$$

$\mathrm{S}_{\beta \mathrm{j}}$ is the estimated value of the standard deviation of regression coefficient $\beta_{\mathrm{j}}$. The larger $\left|\mathrm{t}_{\beta j}\right|$ is, the less likely that $\beta_{\mathrm{j}}$ is 0 , indicating that the independent variable $\mathrm{x}_{\mathrm{j}}$ has more significant effect on dependent variable $y$.

Table 11. Significant $T$ test results.

\begin{tabular}{lllll}
\hline & \multicolumn{2}{l}{ Unstandardized coefficient } & Normalization coefficient & sig. \\
\cline { 2 - 3 } & B & Standard error & Beta & \\
\hline constant & 3.251 & .030 & & .000 \\
Content quality x1 & .472 & .030 & .558 & .009 .636 \\
Technical quality x2 & .233 & .030 & .276 & 15.895 \\
Update frequency x3 & .161 & .030 & .191 & .000 \\
Marketing Quality x4 & .188 & .030 & .223 & .000 \\
\hline
\end{tabular}

From above Table 11, one can see that the parameters of all the independent variables meet $\mathrm{t}$ test at the significance level of $5 \%$, that is, $\operatorname{sig}<0.05$, so the regression coefficients of all independent variables are significant for the satisfaction degree evaluation regression model.

\section{Conclusion}

On the basis of American Customer Satisfaction Index, eight variables are selected to evaluate the satisfaction degree of college students on the knowledge payment platform. Through factor analysis, four factors are extracted as content quality, technical quality, update frequency and marketing quality. Based on the above four factors, a multivariate regression satisfaction degree evaluation model is established. In the constructed satisfaction degree evaluation model, the coefficient of content quality, technical quality, update frequency and marketing quality are $0.472,0.233,0.161,0.188$, respectively. It indicates that the exclusiveness and coverage of the content contributes the most to overall satisfaction, followed by the operability and security of the platform. The model test and empirical analysis show that there is a lot of room for development of future knowledge payment platform, and there are still some problems need to be solved. In order to better improve the satisfaction degree of college students using the knowledge payment platform, the following strategies are suggested for knowledge payment platform.

1. The knowledge payment platform should ensure the comprehensiveness, professionalism, reliability and exclusiveness of knowledge content. Platform operators should collect consumer needs and set up a scoring mechanism to help the platform promote product sales and enhance market competition.

2. The knowledge payment platform should improve the convenience of platform operation and formulate a reliable protective barrier to improve the platform's security operation index.

3. The knowledge payment platform should improve the 
social attributes and timeliness of knowledge content. In order to meet the diversity of people's needs for knowledge content, the platform should strengthen the update frequency of knowledge content and keep up with the pace of change of social information content. Therefore, the platform should deepen internal cooperation and conduct regular update content.

4. The knowledge payment platform should reasonably price the knowledge products and implement an advertising marketing strategy that is consistent with product quality.

5. The government should formulate the relevant policies and regulations for knowledge payment platform, and punish bad content so as to protect the interests of consumers and the intellectual property rights of knowledge producers.

The results of this study make up for the lack of research on customer satisfaction in the knowledge payment field. It not only provides decision basis for improving customer satisfaction and competitiveness of knowledge payment platforms, but also has positive reference significance for the entire knowledge payment field.

\section{Acknowledgements}

This research is supported by the Special Fund for Guangdong University Students' Scientific and Technological Innovation and Cultivation (Climbing Project, No. pdjh2019b0178), and the Natural Science Foundation of Guangdong Province, China (Nos. 2018A030313996 and 2017A030313435).

\section{References}

[1] Media Data, The scale and forecast of knowledge paying users in China from 2015 to 2021. https://data.iimedia.cn/page-category.jsp?nodeid=30406609.

[2] Media Report, 2018-2019 research and business investment decision analysis report on China's knowledge payment industry, 2019, 1, https://www.iimedia.cn/c400/63439.html.

[3] Zhang Yangyi, Review of Knowledge Payment on Online Platforms [J], Information Research, 2018, 8: 129-134.

[4] Yang Shuyi, Comparative Analysis of Chinese and Foreign Knowledge Payment Platforms [J], Information Research, 2019, 6: 83-89.
[5] Ren baijian, Zhang hairong, Li mingjun, Research on the current situation of user behavior of knowledge payment platform [J], Modern business, 2019, 22: 7-8.

[6] Zhao Yang, Yuan xiani, Li luqi, et al., The Impact Factors of Users' Paying Behavior for Knowledge on Social Q\&A Platform Based on Social Capital Theory [J], Library information knowledge, 2018, 4: 15-23.

[7] Zhao Yang, Zhou Ruoxin, Yang Bin, A 2020 perspective on "How knowledge contributor characteristics and reputation affect user payment decisions in paid Q\&A? An empirical analysis from the perspective of trust theory" [J], Electronic Commerce Research and Applications, 2020, 40.

[8] Cao Lihe, Research on theoretical model and evaluation system of customer satisfaction [J], Journal of Hubei University of Economics, 2007, 1: 115-119.

[9] Claes Fornell, Liu jinlan, Kang jian, Bai Yin, American Customer Satisfaction Index [J], Chinese journal of management, 2005, 4: 495-504.

[10] Vinit Dani, Measuring Customer Satisfaction for F\&B Chains in Pune Using ACSI Model [J], Procedia-Social and Behavioral Sciences, 2014, 133: 466-467.

[11] Song Qinqin, A study on Mooc Learners' Satisfaction in Public Art Education in Colleges and Universities [D], Nanjing University of Posts and Telecommunications, 2019: 9-39.

[12] Iman Dianat, Pari Adeli, Mohammad Asgari Jafarabadi, Mohammad Ali Karimi, User-centred web design, usability and user satisfaction: The case of online banking websites in Iran [J], Applied Ergonomics, 2019, 81: 2-3.

[13] She Shihong, Wang Yuting, Empirical research on the correlation between online advertising and online consumption $[\mathrm{J}]$, Modern Communication (Journal of Communication University of China), 2008, 40 (10): 135-138.

[14] Xu Lizhi, Research on the factors affecting the willingness of Zhihu App users to pay [J], Journal of Yanan University, 2019, 38 (03): 23-28.

[15] Araceli Picón-Berjoyo, Carolina Ruiz-Moreno, Ignacio Castro, A mediating and multigroup analysis of customer loyalty $[\mathrm{J}]$, European Management Journal, 2016, 34 (6): 702-703.

[16] Wang Maobin, Empirical study on the influencing factors of consumers' willingness to purchase knowledge paid products [D], Shandong University, 2018: 19-20.

[17] Davis, F. D., Perceived usefulness, perceived ease of use, and user acceptance of information technology, MIS Quarterly, 1989, 13, 319-340. 